\title{
Presentación \\ EDUCACIÓN INTERCULTURAL \\ -ENFOQUES, CAMPOS Y ACTORES EMERGENTES: \\ NOTA INTRODUCTORIA
}

\section{Gunther Dietz}

Universidad Veracruzana

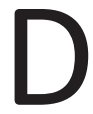

esde la segunda mitad del siglo pasado, y particularmente durante las últimas décadas, la educación intercultural se ha convertido en una propuesta pedagógica novedosa y a menudo heterodoxa. En México, en América Latina y más allá de nuestro continente, modelos, enfoques, programas o proyectospiloto han sido iniciados tanto por el Estado-nación y sus instituciones educativas como por movimientos sociales y sus proyectos educativos propios. Mientras que en los países anglosajones se tiende a una educación "empoderadora" enfocada hacia determinados grupos considerados minoritarios, en la Europa continental se está optando por una educación que transversaliza el fomento de las competencias interculturales de las minorías marginadas, frecuentemente surgidas de procesos migratorios, y sobre todo de las mayorías marginadoras, por ejemplo, las sociedades nacionales autóctonas. En América Latina, por su parte, la educación intercultural aparece como un discurso propio en una fase pos- o neoindigenista -según el caso- de redefinición de relaciones entre el Estado y los pueblos indígenas. Esta "educación intercultural y bilingüe" (Schmelkes, 2013) nace con el afán de superar las limitaciones políticas y pedagógicas de la anterior educación indígena bilingüe y bicultural, y se proclama con cada vez mayor frecuencia "descolonial", pero mantiene un fuerte sesgo hacia el tratamiento preferencial de las cuestiones étnico-indígenas (Dietz, 2017).

El amplio abanico de experiencias que estas diferentes corrientes de la educación intercultural vienen generando dentro y fuera de los sistemas educativos formales ha sido revisado de manera crítica por la investigación educativa desde inicios del milenio; estados del arte como los que Bertely (ed., 2003), Dietz y Mateos (2011) y Bertely, Dietz y Díaz Tepepa (eds., 2013) han presentado para México, López y Küper (2000), López (ed., 2009) y Cortina (ed., 2014) para América Latina y, finalmente, Aguado Odina (2003), Palaiologou y Dietz (eds., 2012), Dietz (2017) y Portera y Grant (eds., 2017) a nivel global, ofrecen un panorama de las aportaciones que la educación intercultural ha logrado hacer para volver los sistemas educativos oficiales y hegemónicos más pertinentes en lo cultural y lingüístico, más contextualizados en cuanto a los aprendizajes situados y colaborativos, más incluyentes en lo curricular y más empoderadores en cuanto a los propios actores educativos, sus saberes-haceres y sus proyectos de vida.

Estos balances de la investigación contemporánea sobre la educación intercultural y sus campos afines reflejan en su conjunto un inusitado aumento exponencial cuantitativo del volumen de investigaciones sobre nuestras temáticas, lo cual ilustra la relevancia que la diversidad y su reconocimiento están obteniendo en los respectivos sistemas educativos nacionales mediante procesos de oficialización "desde arriba", por instancias gubernamentales, pero también de reivindicación y redefinición "desde abajo", por actores comunitarios y redes no gubernamentales. 
Ha habido una ampliación del canon de metodologías y enfoques de investigación, aunque siguen predominando enfoques cualitativos en detrimento de los cuantitativos, que considero serán cada vez más necesarios en el futuro, en particular para impactar en las políticas educativas. Constato una importante presencia de la etnografía y la investigación-acción participativa, pero igualmente se van incorporando -y así lo reflejan los mencionados estados de conocimiento del Consejo Mexicano de Investigación Educativa (COMIE)- métodos colaborativos, descoloniales y "metodologías indígenas". También hay cada vez más investigaciones evaluativas que procuran incorporar una mirada intercultural hacia la evaluación de políticas educativas diseñadas para atender la diversidad cultural, étnica y lingüística.

Ante estos giros recientes de la investigación educativa intercultural, en la edición número 50 de Sinéctica, Revista Electrónica de Educación, hemos convocado a la comunidad académica a presentar las tendencias actuales y las perspectivas emergentes que caracterizarán en el futuro el ámbito de la educación intercultural mexicana y latinoamericana. Algunas temáticas emergentes, varias de las cuales son retomadas y ejemplificadas por las y los autores que contribuyen a este número, son las siguientes:

- Nuevas epistemologías y metodologías de investigación sobre, con y desde los actores de la educación intercultural, que conjugan aportaciones descoloniales, indígenas, comunitarias e interseccionales en sus análisis y propuestas.

- El surgimiento de nuevos modelos, enfoques y programas de educación intercultural en las tensiones e intersticios entre el Estado, el mercado y la sociedad civil, que a menudo acaba profundizando desigualdades educativas y yuxtaponiendo lógicas de redistribución de oportunidades educativas (desde el Estado) con lógicas de lucro (mercado) y lógicas de arraigo comunitario (desde la sociedad civil).

- El diseño, la instrumentación y la evaluación de las políticas actuales de educación intercultural en el marco de presiones internacionales ejercidas por agencias multilaterales para la homologación, acreditación y certificación de las políticas educativas.

- La diversidad lingüística y cultural en las experiencias de educación intercultural bilingüe o multilingüe, que enfrenta no solo un aumento del multilingüismo en aulas escolares, sino, a la vez, capacidades lingüísticas cada vez más diversificadas entre alumnado indígena como no indígena, así como entre alumnado de origen migrante y de origen autóctono.

- El enfoque intercultural en distintos niveles de los sistemas educativos obligatorios y posobligatorios, que oscila entre estrategias de empoderamiento de grupos históricamente discriminados o excluidos de la educación escolar, estrategias de transversalización de "competencias interculturales para todos y todas" y las recientes estrategias de inclusión y educación inclusiva, con sus respectivas propuestas de atención educativa individualizada.

- Las innovaciones educativas y curriculares en la formación de docentes con enfoque intercultural, así como el lugar que ocupa la formación de maestras y maestros indígenas, en particular, dentro de los sistemas nacionales de formación docente, en general. 
-Modelos, programas y actores emergentes de la educación superior intercultural, que difieren en sus funciones de docencia, investigación y vinculación y, asimismo, en su arraigo local y protagonismo de actores indígenas o afrodescendientes, en su titularidad pública (nacional o regional, según el caso) o privada (asociaciones civiles y órdenes religiosas) y en su vocación crítica o funcional en relación con la noción de interculturalidad subyacente (Walsh, 2003).

\section{REFERENCIAS BIBLIOGRÁFICAS}

Aguado Odina, Teresa (2003). Pedagogía Intercultural. Madrid: McGraw-Hill.

Bertely Busquets, María (coord.) (2003). Educación, derechos sociales y equidad, tomo 1. México: COMIE.

Bertely Busquets, María, Dietz, Gunther y Díaz Tepepa, M. Guadalupe (coords.) (2013). Multiculturalismo y educación 2002-2011. México: COMIE/ANUIES.

Cortina, Regina (ed.) (2014). The education of indigenous citizens in Latin America. Bristol, Buffalo, Toronto: Multilingual Matters.

Dietz, Gunther (2017). Interculturalidad: una aproximación antropológica. Perfiles Educativos, vol. 39, núm. 156, pp. 192-207. Recuperado de http://www.iisue. unam.mx/perfiles/articulo/2017-156-interculturalidad-una-aproximacion-antropologica.pdf

Dietz, Gunther y Mateos Cortés, Laura Selene (2011). Interculturalidad y educación intercultural en México: un análisis de los discursos nacionales e internacionales en su impacto en los modelos educativos mexicanos. México: SEP-CGEIB.

López, Luis Enrique (ed.) (2009). Interculturalidad, educación y ciudadanía: perspectivas latinoamericanas. La Paz: FUNPROEIB \& Plural Editores.

López, Luis Enrique y Küper, Wolfgang (2000). La educación intercultural bilingüe en América Latina. Recuperado de www.schwartzman.org.br/simon/delphi/pdf/lopes_comp1.pdf

Palaiologou, Nektaria y Dietz, Gunther (eds.) (2012). Mapping the broad field of intercultural and multicultural education worldwide: Towards the construction of a new citizen. Newcastle upon Tyne: Cambridge Scholars Publishing.

Portera, Agostino y Grant, Carl A. (eds.) (2017). Intercultural education and competences: Challenges and answers for the global world. Newcastle upon Tyne: Cambridge Scholars Publishing.

Schmelkes, Sylvia (2013). Educación para un México intercultural. Sinéctica, núm. 40, pp. 1-12. Recuperado de https://sinectica.iteso.mx/index.php/SINECTICA/article/ view/48

Walsh, Catherine (2003). Interculturalidad y colonialidad del poder: un pensamiento y posicionamiento otro desde la diferencia colonial. En C. Walsh, Á. García Linera y W. Mignolo (eds.). Interculturalidad, descolonización del estado y del conocimiento (pp. 21-70). Buenos Aires: Ediciones del Signo.

DOI: 10.31391/S2007-7033(2018)0050-001 